\title{
RANCANG BANGUN JARINGAN WI-FI UNTUK KOMUNIKASI DARING DI DESA TENJOLAYA
}

\author{
${ }^{1}$ Yuli Kurnia Ningsih, ${ }^{2}$ Nazmia Kurniawati \\ 1,2Jurusan Teknik Elektro, Fakultas Teknologi Industri, Universitas Trisakti \\ Email: ${ }^{1}$ yuli_kn@trisakti.ac.id, ${ }^{2}$ nazmia.kurniawati@trisakti.ac.id
}

\begin{abstract}
Abstrak
Tersedianya infrastruktur telekomunikasi mempengaruhi kemajuan suatu daerah, terutama daerah yang memiliki potensi pariwisata dan hasil pertanian seperti Desa Tenjolaya. Pembangunan RT RW net sebagai infrastruktur jaringan internet dengan menggunakan teknologi $W i-F i$ dapat menjadi sektor pendukung kemajuan ekonomi desa tersebut. Pembangunan jaringan dilakukan dalam tiga tahap: persiapan, pembangunan, dan pengukuran. Pada tahap persiapan, dilakukan kalkulasi jumlah pengguna dan survey lokasi pemasangan. Selanjutnya dilakukan pembangunan jaringan berdasarkan arsitektur jaringan yang telah dirancang dengan CPE yang berjumlah empat titik. Pada tahap akhir dilakukan pengukuran empat parameter untuk memeriksa kondisi jaringan. Ke-empat parameter tersebut adalah throughput, signal strength, CCQ, dan SNR. Dari hasil pengukuran, throughput yang terukur di access point memiliki rentang nilai 17 hingga $30 \mathrm{dBm}$. Tx signal strength terukur memiliki nilai -75 hingga $-39 \mathrm{dBm}$ sementara Rx signal strength terukur bernilai antara -72 hingga -37 $\mathrm{dBm}$. Untuk nilai CCQ bernilai antara 76 hingga 100\%. Parameter SNR terukur memiliki nilai 38 hingga $77 \mathrm{dBm}$.
\end{abstract}

Kata Kunci: Wi-Fi, Internet, Jaringan

\begin{abstract}
The availability of telecommunication infrastructure affects the development of an area, especially areas that have the potential for tourism and agricultural products such as Tenjolaya Village. The development of $R T R W$ net as internet network infrastructure using Wi-Fi technology can be a supporting sector for the economic development of the village. Network deployment is carried out in three stages: preparation, construction and measurement. In the preparation stage, the number of users is calculated and a survey of the installation location is carried out. Furthermore, network development is carried out based on the network architecture that has been designed with CPE totaling four points. In the final stage, four parameters are measured to check the network conditions. The parameters are throughput, signal strength, CCQ, and SNR. From the measurement results, the measured throughput at the access point has a value range of 17 to $30 \mathrm{dBm}$. The measured Tx signal strength has a value of -75 to $-39 \mathrm{dBm}$ while the Rx signal strength is between -72 to $-37 \mathrm{dBm}$. The CCQ value is between 76 and 100\%. The measured SNR parameter has a value of 38 to $77 \mathrm{dBm}$.
\end{abstract}

Keywords: Wi-Fi, Internet, Network

\section{PENDAHULUAN}

Ketersediaan infrastruktur telekomunikasi merupakan salah satu faktor yang paling berpengaruh dalam kemajuan suatu daerah. Berdasarkan (Roller \& Waverman, 2001), dalam 20 tahun terakhir, 21 negara anggota yang tergabung dalam the Organization for Economic Co-operation and Development (OECD) melaporkan peningkatan pesat dalam bidang ekonomi yang disebabkan oleh keberadaan infrastruktur dan pemanfaatan jaringan telekomunikasi di negaranya. Berdasarkan hasil 
survey pada (We_are_Social and Hootsuite, 2019), dari 7.7 milyar penduduk dunia terdapat 4.4 milyar pengguna jaringan internet. Hal tersebut menunjukkan $57 \%$ dari total penduduk di seluruh dunia telah memanfaatkan internet dan menjadikannya bagian dalam hidup sehari-hari. Di Indonesia sendiri pengguna internet telah mencapai $56 \%$ dari 286.2 juta penduduk dengan $60 \%$ pengguna menggunakan telepon pintar dan $22 \%$ menggunakan laptop atau computer desktop serta sisanya menggunakan perangkat lain seperti tablet (Kemp, 2019). Jumlah ini menandakan terdapat kebutuhan yang tinggi terhadap koneksi internet di Indonesia. Namun sayangnya jaringan internet sendiri masih belum sepenuhnya menjangkau daerah-daerah di Indonesia. Dari hasil survey yang sama (Kemp, 2019), hanya $42.67 \%$ wilayah Indonesia yang sudah dapat menikmati jaringan internet di daerahnya. Dari angka tersebut menunjukkan masih banyak wilayah di Indonesia yang membutuhkan infrastruktur telekomunikasi sehingga dapat menikmati layanan internet di daerahnya.

Tenjolaya merupakan sebuah desa yang berlokasi di kaki Gunung Salak, Sukabumi, Jawa Barat. Lokasinya yang berada di kaki gunung menyebabkan desa ini memiliki pemandangan yang indah dan hasil bumi yang melimpah sehingga memiliki potensi besar dalam bidang pariwisata dan pertanian. Di bidang pariwisata, terdapat beberapa objek wisata seperti Situs Cagar Budaya Batu Kujang (Dinas Pariwisata dan Kebudayan Provinsi Jawa Barat, 2011) dan Taman Pijat Kaki Batu Ceria (Sukabumi Update, 2018). Di bidang pertanian terdapat beberapa hasil bumi seperti kopi, beras, dan bunga potong. Selain itu dengan sumber air yang melimpah terdapat pula beberapa kolam ikan seperti mujair dan nila. Dengan posisi yang berada di kaki gunung menyebabkan kontur daerahnya berbukitbukit. Kontur tanah yang berbukit tersebut menyebabkan banyak titik yang tidak terjangkau oleh sinyal komunikasi, terutama wilayah yang berada di bagian lembah. Sehingga diperlukan solusi alternatif untuk menyediakan layanan internet di Desa Tenjolaya.

RT RW Net merupakan jaringan internet swadaya yang dapat digunakan untuk memberikan layanan internet dalam skala kecil dengan memanfaatkan teknologi Wireless Fidelity (Wi-Fi) atau jaringan lokal menggunakan kabel. Biaya pembangunan dan perawatan jaringannya relatif lebih murah dan dapat dikonfigurasi sesuai dengan kebutuhan. Selain itu waktu pembangunannya juga dapat dilakukan dengan cepat.
Pada paper ini dipaparkan proses pembangunan jaringan RT RW Net di Desa Tenjolaya yang dimulai dengan survey wilayah, perencanaan arsitektur jaringan dan perangkat yang digunakan, instalasi jaringan, dan diakhiri dengan pengetesan untuk menentukan apakah jaringan yang dibangun memiliki kualitas yang baik atau tidak. Berikut adalah struktur paper ini. Bagian pertama menjabarkan latar belakang diperlukannya jaringan internet di Desa Tenjolaya. Bagian selanjutnya menjelaskan fase persiapan yang dilakukan sebelum membangun jaringan, seperti survey site, perencanaan topologi jaringan dan perangkat yang digunakan. Bagian berikutnya menjelaskan proses instalasi dan pengetesan jaringan. Selanjutnya dilakukan analisa terhadap hasil pengetesan. Pada bagian akhir diambil kesimpulan dan rencana selanjutnya untuk meningkatkan kualitas layanan.

\section{TAHAP PERSIAPAN}

Sebelum mulai membangun jaringan, survey area perlu dilakukan untuk mengetahui kondisi daerah yang akan dilayani. Desa Tenjolaya memiliki kontur tanah yang berbukit-bukit yang membentang dari arah barat laut hingga tenggara Gunung Salak dengan ketinggian 515-1170 meter di atas permukaan laut (mdpl). Luas Desa Tenjolaya sekitar 497 Hektar dengan hanya 45 Hektar yang dimanfaatkan untuk bangunan (Badan Pusat Statistik Kabupaten Sukabumi, 2019). Berdasarkan hasil sensus Badan Pusat Statistik, penduduk Desa Tenjolaya berjumlah 5497 jiwa dengan laju pertumbuhan sebesar 0.38 (Badan Pusat Statistik Kabupaten Sukabumi, 2019) dan rasio penduduk usia produktif (15-64 tahun) sebesar 65\% (BPS Kabupaten Sukabumi, 2018). Jumlah penduduk usia produktif yang lebih dari setengah jumlah penduduk menunjukkan tingginya potensi akan kebutuhan internet di Desa Tenjolaya. Gambar 1(a) menunjukkan lokasi wilayah Desa Tenjolaya dan Gambar 1(b) profil ketinggian yang diambil dari Google Earth.

Setelah mengetahui kondisi area Desa Tenjolaya melalui Google Earth, selanjutnya dilakukan kunjungan ke area tersebut untuk mengetahui kondisi real lingkungan Desa Tenjolaya. Hal ini juga bertujuan untuk merencanakan lokasi penempatan Customer Premises Equipment (CPE) dan ketinggian tower untuk peletakkan antenna dan perangkat Wi-Fi.

Berdasarkan data yang didapatkan dari hasil survey, Desa Tenjolaya memiliki banyak area terbuka berupa sawah, kebun, dan kolam. Sementara itu pemukiman penduduk terpusat hanya di area 
tertentu. Oleh karena itu area perumahan penduduk menjadi prioritas utama yang akan dilayani dan area terbuka akan diabaikan. Menimbang kondisi lingkungan dan posisi pemukiman penduduk, kombinasi jaringan nirkabel dan serat optik digunakan untuk jaringan $\mathrm{rt}$ rw net. Jaringan nirkabel digunakan sebagai jaringan distribusi antara pengguna dengan hotspot. Sementara itu kabel serat optik digunakan sebagai penghubung jaringan backbone.

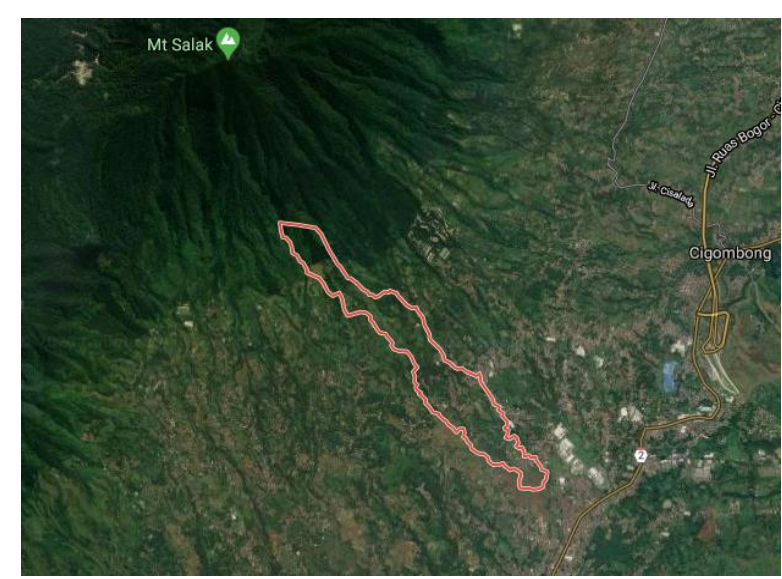

(a)

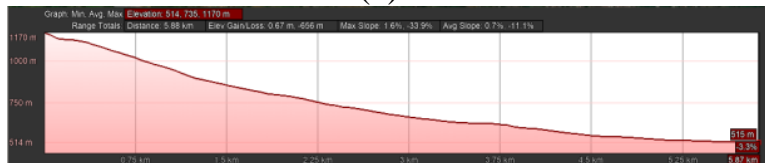

(b)

Gambar 1. (a) Lokasi Wilayah Desa Tenjolaya (b) Profil Ketinggian

Untuk tahap awal, wilayah yang akan dilayani oleh jaringan adalah wilayah sebelah barat laut atau bagian atas desa. Hal tersebut disebabkan pada area tersebut terdapat beberapa villa yang sering dikunjungi oleh wisatawan. Dari hasil survey lapangan yang dilakukan, didapatkan 8 titik pemasangan perangkat seperti yang disebutkan dalam Tabel 1 dan Gambar 2.

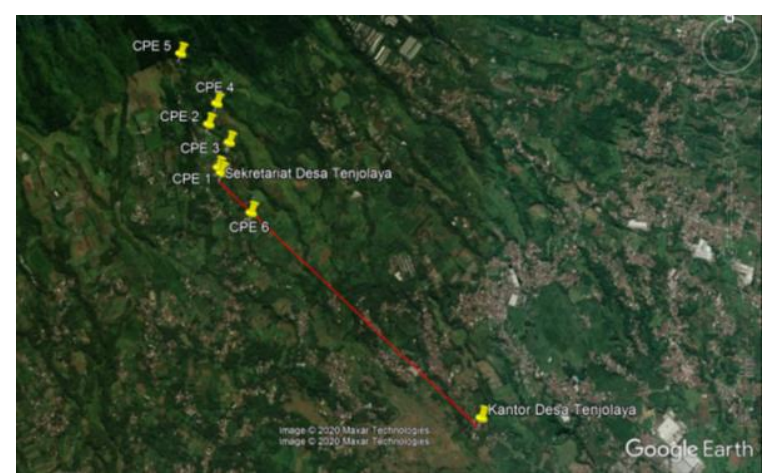

Gambar 2. Lokasi Pemasangan Perangkat
Tabel 1. Lokasi Pemasangan Perangkat

\begin{tabular}{|c|c|c|c|}
\hline No & Nama & Koordinat & $\begin{array}{c}\text { Ketinggian } \\
(\mathrm{mdpl})\end{array}$ \\
\hline 1 & $\begin{array}{l}\text { Kantor } \\
\text { Desa }\end{array}$ & $\begin{array}{l}6^{\circ} 46^{\prime} 6.12 " \mathrm{~S} \\
106^{\circ} 46^{\prime} 5.11 \text { "E }\end{array}$ & 550 \\
\hline 2 & $\begin{array}{l}\text { Sekretariat } \\
\text { Desa }\end{array}$ & $\begin{array}{l}6^{\circ} 45^{\prime} 7.82^{\prime \prime S} \\
106^{\circ} 45^{\prime} 3.32 \text { "E }\end{array}$ & 776 \\
\hline 3 & CPE 1 & $\begin{array}{l}6^{\circ} 45^{\prime} 9.14 " \mathrm{~S} \\
106^{\circ} 45^{\prime} 4.10^{\prime \prime} \mathrm{E}\end{array}$ & 769 \\
\hline 4 & CPE 2 & $\begin{array}{l}6^{\circ} 44^{\prime} 57.09 " \mathrm{~S} \\
106^{\circ} 45^{\prime} 0.65 " \mathrm{E}\end{array}$ & 816 \\
\hline 5 & CPE 3 & $\begin{array}{l}6^{\circ} 45^{\prime} 1.61 " \mathrm{~S} \\
106^{\circ} 45^{\prime} 5.79^{\prime \prime} \mathrm{E}\end{array}$ & 792 \\
\hline 6 & CPE 4 & $\begin{array}{l}6^{\circ} 44^{\prime} 51.87 " \mathrm{~S} \\
106^{\circ} 45^{\prime} 2.47^{\prime \prime E}\end{array}$ & 828 \\
\hline 7 & CPE 5 & $\begin{array}{l}6^{\circ} 44^{\prime} 39.13 " \mathrm{~S} \\
106^{\circ} 44^{\prime} 53.17^{\prime \prime} \mathrm{E}\end{array}$ & 924 \\
\hline 8 & CPE 6 & $\begin{array}{l}6^{\circ} 45^{\prime} 18.81 " \mathrm{~S} \\
106^{\circ} 45^{\prime} 11.44^{\prime \prime} \mathrm{E}\end{array}$ & 725 \\
\hline
\end{tabular}

Pada kantor desa, diletakkan perangkat server dan router yang digunakan untuk mengatur jaringan. Kantor desa dipilih karena keamanan perangkat terjamin dan dapat dengan mudah diakses. Di kantor desa juga dipasang antenna directional yang menembakkan sinyal ke sekretariat desa. Antara perangkat server dengan radio di kantor desa dihubungkan menggunakan kabel serat optik. Selebihnya komunikasi antar perangkat jaringan memanfaatkan jalur nirkabel. Pada sekretariat desa, sinyal yang diterima dari antena di kantor desa disebar ke beberapa access point yang terpasang di rumah penduduk. Selanjutnya penduduk dapat menghubungkan gawainya ke access point yang terpasang. Pada Gambar 3 ditampilkan arsitektur jaringan yang dipasang di Desa Tenjolaya.

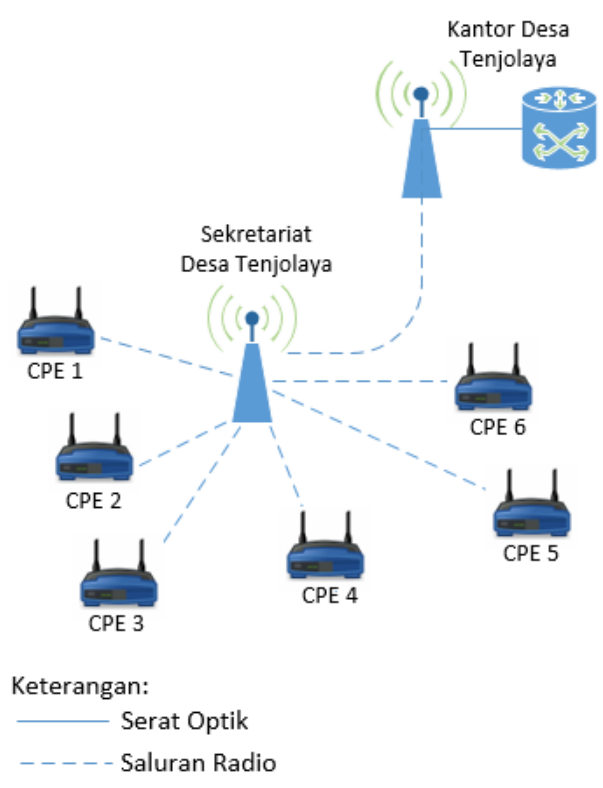

Gambar 3. Arsitektur Jaringan di Desa Tenjolaya 


\section{PEMBANGUNAN DAN PENGUKURAN} JARINGAN

\section{A. Pembangunan Jaringan}

Pada tahap ini dilakukan pembangunan jaringan sesuai dengan rencana yang telah dibuat. Antenna yang terpasang di kantor desa dan secretariat desa diletakkan di area outdoor sehingga sinyal Wi-Fi dapat mencapai rumah pelanggan.

Pada tahap awal dilakukan mediasi dengan penduduk setempat yang lahannya akan digunakan untuk pemasangan tower. Hal ini penting dilakukan untuk menghindari terjadinya konflik di masa depan. Setelah izin didapatkan maka tahap selanjutnya adalah pembangunan tower.

Tower yang digunakan berupa tiang besi dengan rekomendasi ketinggian sekitar $3 \mathrm{~m}$. Tipe tower yang dipilih adalah tipe triangle. Tiang tipe ini dipilih karena pemasangannya tidak membutuhkan lahan yang luas namun dapat menahan beban antena yang dipasang. Untuk pemasangan seluruh tower dibutuhkan waktu sekitar 1 bulan dengan tiga orang installer yang bertugas memasang pondasi, tower, grounding, dan antenna.

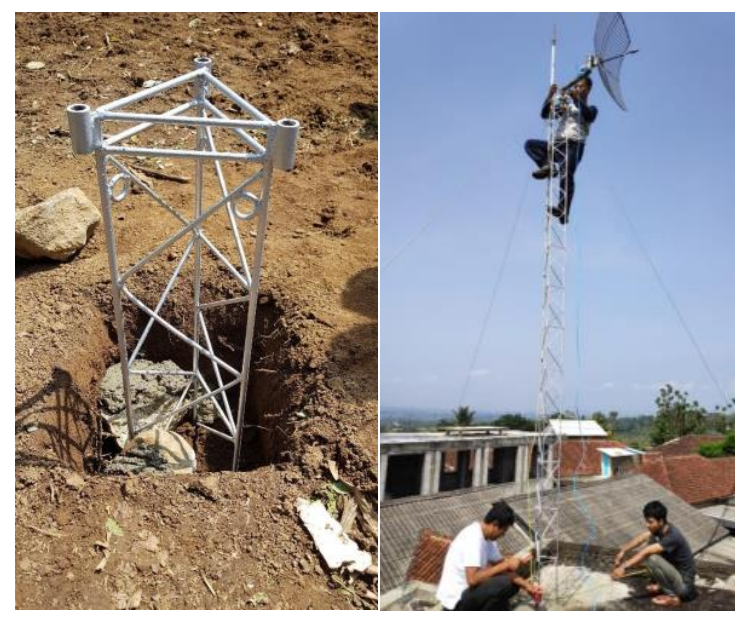

Gambar 4. Tower yang digunakan untuk jaringan

\section{B. Pengukuran Jaringan}

Pada tahap ini dilakukan pengukuran untuk mengetahui kualitas jaringan yang telah dipasang. Terdapat 4 (empat) parameter yang dites: throughput, signal strength, Client Connection Quality (CCQ), dan Signal to Noise Ratio (SNR).

Dari enam CPE yang rencananya akan dipasang, hanya empat $\mathrm{CPE}$ yang berhasil dipasang, yaitu CPE 2, 3, 4, dan 5. Dua CPE gagal terpasang disebabkan oleh hal teknis dan non-teknis. Berikut ini adalah hasil pengetesan dari empat CPE yang terpasang.

Pada tabel berikut ini menunjukkan perangkat yang dipasang.
Tabel 2. Perangkat yang Dipasang

\begin{tabular}{|c|c|c|c|}
\hline No & Perangkat & Jumlah & Keterangan \\
\hline 1 & $\begin{array}{l}\text { Tower } \\
\text { Triangle } \\
\end{array}$ & 8 & \\
\hline 2 & Grounding & 3 & $\begin{array}{l}\text { Sebagai pengaman } \\
\text { terhadap petir }\end{array}$ \\
\hline 3 & $\begin{array}{l}\text { Router } \\
\text { RB4011 }\end{array}$ & 1 & \\
\hline 4 & $\begin{array}{l}\text { Cambium } \\
\text { Epmp Force } \\
200\end{array}$ & 4 & \\
\hline 5 & $\begin{array}{l}\text { Switch HP } 8 \\
\text { Port Gigabit }\end{array}$ & 9 & \\
\hline 6 & $\begin{array}{l}\text { Accessoris } \\
\text { Instalasi }\end{array}$ & 10 & \\
\hline 7 & $\begin{array}{l}\text { Antena } \\
\text { Sectoral }\end{array}$ & 4 & \\
\hline 8 & Unifi AP LR & 10 & $\begin{array}{l}\text { Sebagai CPE untuk } \\
\text { pelanggan }\end{array}$ \\
\hline 9 & CPE LHG & 6 & \\
\hline 10 & $\begin{array}{l}\text { FO Drop } \\
\text { Core }\end{array}$ & 120 & \\
\hline 11 & $\begin{array}{l}\text { Konverter } \\
\text { FO + } \\
\text { Splicing } \\
\end{array}$ & 1 & \\
\hline
\end{tabular}

\section{1) Throughput}

Throughput menunjukkan kcepatan laju data di dalam jaringan dan dihitung dalam satuan bit per second (bps) (Jyothi, Singla, Godfrey, \& Kolla, 2016). Bit per second sendiri menunjukkan berapa jumlah bit informasi yang dilewatkan oleh jaringan dalam satu detik. Pengukuran dilakukan di sisi CPE. Nilai throughput yang diperoleh adalah hasil pengukuran antara antenna di sekretariat desa dengan masing-masing CPE.

Dari Gambar 5 dapat dilihat bahwa nilai throughput terendah terukur di CPE 4 dengan nilai 17 Mbps dan throughput tertinggi terukur di CPE 2 dan CPE 5 dengan nilai $30 \mathrm{Mbps.}$

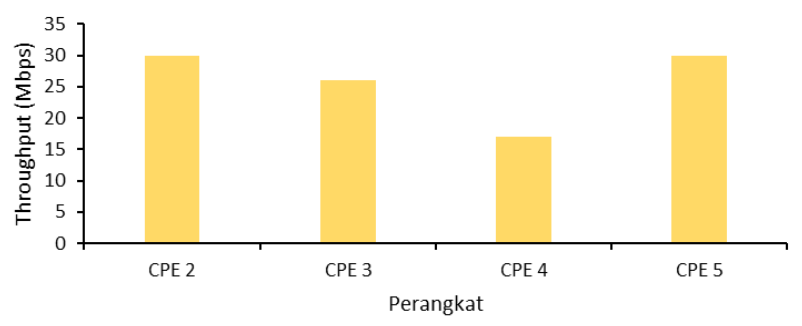

Gambar 5. Hasil Pengukuran Throughput

\section{2) Signal Strength}

Signal strength menunjukkan seberapa kuat sinyal yang dipancarkan atau diterima oleh perangkat (Lipfert \& Martin, n.d.). Tx signal strength menunjukkan kuat sinyal yang dipancarkan oleh perangkat CPE. Sedangkan Rx signal strength 
menunjukkan kuat sinyal yang diterima oleh CPE dari sinyal yang dipancarkan oleh antenna di sekretariat desa. Signal strength diukur dalam satuan $\mathrm{dBm}$.

Dari Gambar 6 dapat dilihat terdapat perbedaan nilai daya pancar setiap CPE. Signal strength tertinggi dimiliki CPE 2 dengan TX signal strength $-39 \mathrm{dBm}$ dan terendah dipancarkan oleh CPE 4 dengan nilai $-75 \mathrm{dBm}$. Sedangkan Rx signal strength paling tinggi terukur di CPE 2 dengan nilai $-37 \mathrm{dBm}$ dan terendah terukur di CPE 4 dengan nilai -72 $\mathrm{dBm}$.

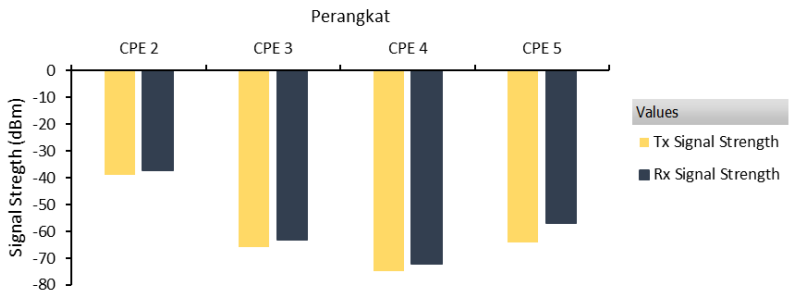

Gambar 6. Hasil Pengukuran Tx/Rx Signal Strength

\section{3) $\mathrm{CCQ}$}

CCQ menunjukkan perbandingan antara bandwidth yang digunakan dengan bandwidth yang tersedia (Mikrotik Wiki Team, 2020). Nilai CCQ berhubungan nilai throughput. Semakin tinggi nilai CCQ maka semakin baik kualitas jaringan.

Pada Gambar 7 terlihat bahwa nilai CCQ tertinggi dimiliki oleh CPE 5 sebesar 100\%. Hal ini menunjukkan bahwa seluruh bandwidth yang tersedia dapat digunakan oleh informasi. Sedangkan nilai CCQ terendah terukur pada CPE 4 dengan nilai $76 \%$. Hal tersebut menunjukkan bahwa $24 \%$ dari bandwidth yang tersedia tidak dapat digunakan untuk melewatkan informasi. Hal tersebut dapat disebabkan oleh tingginya nilai noise/interferensi yang berada di sekitar area CPE 4 .

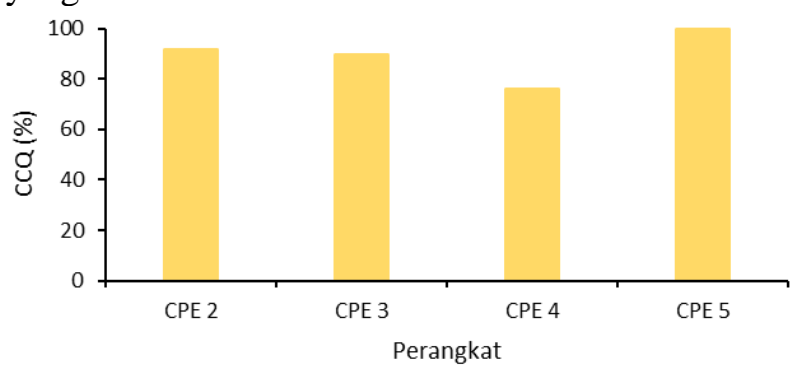

Gambar 7. Hasil Pengukuran CCQ

\section{4) SNR}

Parameter SNR menunjukkan perbandingan kuat sinyal yang diterima oleh perangkat dengan level noise (Welvaert \& Rosseel, 2013). Semakin tinggi level noise maka semakin rendah nilai SNR. SNR dihitung dalam satuan $\mathrm{dB}$.

Pada Gambar 8 dapat dilihat bahwa nilai SNR tertinggi terukur pada CPE 2 dengan nilai $77 \mathrm{~dB}$ dan
SNR terendah terukur di CPE 4 dengan nilai $38 \mathrm{dBm}$. Seperti terlihat pada Gambar 7 bahwa nilai CCQ terendah terukur pada CPE 4. Hal tersebut disebabkan karena tingginya level noise yang terukur di CPE 4. Hal tersebut menyebabkan nilai SNR pada CPE 4 menjadi yang terendah.

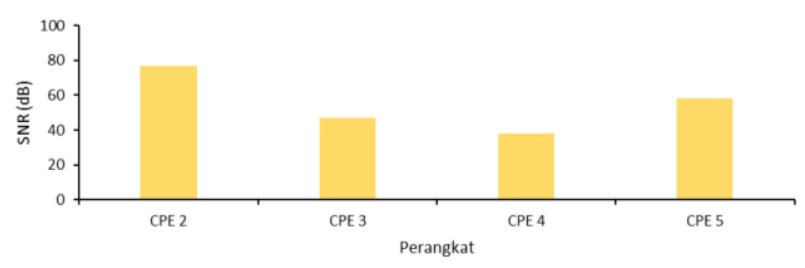

Gambar 8. Hasil Pengukuran SNR

\section{PENUTUP}

\section{Kesimpulan}

Pada paper ini dilakukan pembangunan jaringan $\mathrm{Wi}$ $F i$ di Desa Tenjolaya yang terdiri atas tiga tahapan: persiapan, pembangunan, dan pengukuran. Pada tahap persiapan dilakukan estimasi jumlah pengguna dan lokasi pemasangan access point. Pada tahap selanjutnya dilakukan pemasangan access point di empat titik sesuai dengan arsitektur yang dibuat. Tahap terakhir dilakukan pengukuran parameter throughput, signal strength, CCQ, dan SNR. Dari hasil pengukuran nilai throughput tertinggi terukur di CPE 2 dan 5 dengan nilai sebesar 30 Mbps. Tx signal strength terkuat terukur di CPE 2 dengan nilai $-39 \mathrm{dBm}$ dan Rx signal strength terkuat juga terukur di CPE 2 dengan nilai $-37 \mathrm{dBm}$. CCQ 100\% terukur pada CPE 5. SNR terbaik terukur pada CPE 2 dengan nilai $77 \mathrm{~dB}$. Dari hasil pengukuran dapat diketahui bahwa jaringan yang dibangun dapat digunakan oleh warga Desa Tenjolaya berkomunikasi melalui jaringan internet..

\section{Saran}

Sebagai pengembangan dapat ditambahkan proxy server atau server aplikasi yang dapat memberikan layanan yang lebih beragam.

\section{DAFTAR PUSTAKA}

Badan Pusat Statistik Kabupaten Sukabumi. (2019). Kecamatan Cicurug 2019 Dalam Angka . Sukabumi: Badan Pusat Statistik Kabupaten Sukabumi.

BPS Kabupaten Sukabumi. (2018, 11 24). Proyeksi Penduduk Kabupaten Sukabumi Menurut Kelompok Umur, 2013-2020. Retrieved 08 18, 2020, from Badan Pusat Statistik Kabupaten Sukabumi: 
https://sukabumikab.bps.go.id/statictable/2

018/11/24/69/proyeksi-penduduk-

kabupaten-sukabumi-menurut-kelompok-

umur-2013-2020-.html

Dinas Pariwisata dan Kebudayan Provinsi Jawa

Barat. (2011, 12 30). Situs Batu Kujang I

dan II. Retrieved 08 18, 2020, from

disparbud jabar:

http://www.disparbud.jabarprov.go.id/wisa

ta/dest-det.php?id=154\&lang=id

Jyothi, S. A., Singla, A., Godfrey, P. B., \& Kolla,

A. (2016). Measuring and Understanding

Throughput of Network Topologies. SC

16: Proceedings of the International

Conference for High Performance

Computing, Networking, Storage and

Analysis (pp. 761-772). Salt Lake City:

IEEE.

Kemp, S. (2019). Digital 2019: Indonesia -- Data

Reportal -- Global Digital Insights. Data

Reportal, 77.

Lipfert, F., \& Martin, T. (n.d.). Signal Strength.

Retrieved September 25, 2020, from

SPEEDCHECK:

https://www.speedcheck.org/wiki/signal-

strength/

Mikrotik Wiki Team. (2020, September 7).

Manual:Wireless FAQ. Retrieved

September 25, 2020, from Mikrotik

Documentation:

https://wiki.mikrotik.com/wiki/Manual:Wir eless_FAQ

Roller, L. H., \& Waverman, L. (2001).

Telecommunications Infrastructure and Economic Development: A Simultaneous Approach. American Economic Review Vol. 91 No. 4, 909-923.

Sukabumi Update. (2018, 01 14). Batu Ceria, Wisata Refleksi Kaki Gratis di Desa Tenjolaya Kabupaten Sukabumi. Retrieved 08 18, 2020, from Kumparan:

https://kumparan.com/sukabumiupdate/batu-ceria-wisata-refleksi-kakigratis-di-desa-tenjolaya-kabupatensukabumi

We_are_Social and Hootsuite. (2019). Digital 2019 Essential Insights Into How People Around The World Use The Internet, Mobile Devices, Social Media, and E-Commerce. We Are Social, Hootsuite, 76. 